Cell Physiol Biochem 1995;5:410-411

\title{
Subject Index Vol. 5, 1995
}

Acetylcholine 118, 344 N-Acetylcysteine 399 Acidification 1 Adenine nucleotides 96 Adenylate cyclase 118,318 Adriamycin 399 Airway epithelium 385 Amiloride 330,385/ / Aminohippurate transport 290 Aminopeptidase N 127 Angiotensin II 176 Antiporter 330 L-Arginine 176 Atherosclerosis 318 ATP 344

Benzamil 385

Ca2+-free solution 211

Caffeine 193,330

Calcium 45,135,193, 330, 344

antagonists 155

channel 10

paradox 330 Carbachol 204 CBP14 33

Cell Ca2+ measurements 286

culture 353

damage 135

line 222

membrane potential 252

proliferation $269 \mathrm{c}$-fos 155 Channel 23

Chelerythrine chloride 211 Chloride 222

- channel 259

Chromanol 204

Cl channel 118

Cl- conductance 243

- $\quad$ secretion 204

C1C-2 channel 243

Codeine 290

Collagenase 353

Colloidal gold 85

Colon 204

Coronary heart disease 318 Cortical collecting duct 222 Corticosterone 167 Cortisol 167

Creatine kinase 135,193

- $\quad$ - release 45

Cyclic adenosine monophosphate . 318,380

- guanosine monophosphate

318,380

nucleotides 127 Cyclopiazonic acid 299,371 Cystic fibrosis 385 Cytoskeleton 361 Cytosolic

$\mathrm{Ca} 2+232$

inhibitor 259

Diarrhea 23 DIDS 243 
2,4-Dinitrophenol 330 Dopamine receptors 118 DPC 243 Drosophila 313 Duct cell line 232 Ducts 344

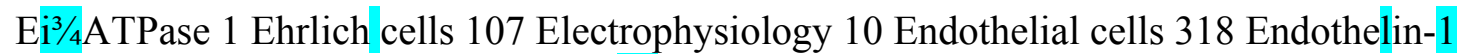
155,176 Endothelium 85 Epithelium 118 Erythroblasts 96 Erythrocyte metabolism 391 Estradiol 318

Fetal calf serum 286

- development 167

Fluid absorption 118

Fos 313

Fura-2 286,299,344,371

Galactoside-binding protein 33 Gallbladder epithelium 211 Gap junction resistance 211

Gene expression 276 Glibenclamide 222 Glomerular mesangial cell 127 Glucocorticosteroid metabolism

167 Glucocorticosteroids 167 Glycolysis 299 Gold-protein-substance P 85 Granular ducts 243 Growth factors 127,145

$\mathrm{H} 20245$

H7 211

H,K-ATPase 1

Halothane 10

Heart 45

Heat shock 313

Hepatocytes 252

HT29 cells 259

Human choriogonadotropin 361

- $\quad$ placenta 259

1 1B-Hydroxysteroid dehydroge-

nase 167 Hypertension 276

Inhibitor 269 Intestine 23 Intracellular $\mathrm{Ca} 2+371$

messengers 380

pH 299,371 Ion channel 222 Isolated glomeruli 399 Isoproterenol 391

$\mathrm{K}+$ channel(s) 145

- blocker(s) 204,232

conductance 252 Kidney 1,353 Kinase 23

Lectin 33

LH/CG receptor $361 \mathrm{Li}+/ \mathrm{Na}+$ exchanger 391 Lymphocyte 269,276 Lysophosphatidic acid 145 410

Western blot 1145

Malignant hyperthermia 10 Menadione 45,135 Mesangial cell(s) 155,176 $\mathrm{N}^{\wedge}$ Methylnicotinamide transport

290 Mitogens 127

Mouse mandibular glands 243 Muscarinic receptor 232 Muscle damage 193 -, smooth, vascular 276 Myxine glutinosa 399

$\mathrm{Na}+/ \mathrm{H}+$ exchange 269,276

- $\quad$ exchanger 391

$\mathrm{Na}+$ absorption 385 
$\mathrm{Na} \mid \mathrm{K}+, 2 \mathrm{Cl}$ - cotransporter 107

Necturus 211

Neurokinin receptor 85 Nucleus 33

11ß-OHSD 167 Osmolality 243 Ovary, cow 380 Oxygen radicals 45 Oxytocin 380

Pancreas 344

Patch clamp 232, 344

- $\quad$ clamping 145

$\mathrm{pH}$ regulation 269,276

Phosphodiesterase 318

Pig coronary artery 85

Pigs 10

Placenta 167

Planar lipid bilayer 10

Polyclonal antibodies 107

Potassium absorption 1

Proliferating cell nuclear antigen

155 Proliferation 155,276 Protein kinase C 313

- inhibitors 211

synthesis 399 Proteolytic degradation 399 Proto-oncogenes 155 Proximal tubular cells 353

Purine catabolism 96 Pyridine nucleotides 96

Rat 1

kidneys 290 Receptor clustering 361

protein tyrosine kinases Renal cells 371

epithelial cells 222

proximal tubules 286 Reticulocytes 96 RNA synthesis 399

Secretin 344 Serotonin 252 Signal transduction 313 Skeletal muscle 10 Small intestine 118

SNARF-1 299,371 Stress 313

T84 cells 23 Testosterone 318 Thapsigargin 299, 371 Thebaine 290

Tight junction resistance 211 Tissue culture medium 286 Trout erythrocytes 391

Vasopressin 380 Verapamil 155 Viability 353 VSM cells 299 